\title{
PERKEMBANGAN TARI KLASIK \\ GAYA YOGYAKARTA DI ERA GLOBAL
}

Titik Putraningsih

FBS Universitas Negeri Yogyakarta

\section{Abstract}

The development of Yogyakarta classical dances in this global era is influenced by the advance of technology, the spread of tourism industries and the change of aesthetic taste of urban society. This article discusses how art lovers and artists face the global challenges and survive in the era. Dance experts create innovative forms of dances that are easy to learn; Dance organizations establish educational programs for dance learning; Dance education produces individuals who grow into dancers, or teachers in both formal and informal education. Moreover, dance organizations also produce new generation who will maintain, preserve and develop the classical dances in the future.

Key Words: Yogyakarta classical dances, dance organizations, the global era

\section{A. Pendahuluan}

Saat ini kondisi kehidupan seni tari di keraton Yogyakarta sedang lesu dan memerlukan dukungan dari lembaga pendidikan formal seperti Sekolah Menengah Kejuruan I Bantul (SMKI), Institut Seni Indonesia Yogyakarta, Universitas Negeri Yogyakarta, dan organisasi tari yang berkembang di luar keraton Yogyakarta. Sejarah kehidupan seni pertunjukan di Indonesia tidak akan terlepas dari perkembangan berbagai aspek kehidupan yang berkaitan dengan politik, sosial, dan ekonomi. Tari istana yang disebut seni adi luhung semula hanya dinikmati oleh kaum bangsawan kemudian berkembang ke luar istana, sehingga masyarakat luas bisa turut menikmati dan mempelajarinya. Sultan Hamengku Buwono VII mengijinkan orang-orang di luar keraton untuk belajar tari istana tetapi kegiatannya di luar tembok keraton. Pada tahun 1918 berdirilah organisasi tari Krida Beksa Wirama yang dipelopori oleh dua putra Sultan yaitu Pangeran Tedjokusuma dan Pangeran Soeryodiningrat. (Fred Wibowo, ed., 1981, 221-222).

Pada masa perang kemerdekaan kegiatan kesenian di keraton Yogyakarta terhenti. Pada tahun 1951 untuk mengembangkan kesenian kraton, Sultan memindahkan kegiatan kesenian di dalem Purwadiningratan. Hal ini dimaksudkan untuk menampung para peminat seni tari dan karawitan di luar keraton. Perkembangan berikutnya muncul beberapa organisasi tari lainnya yaitu: Irama Citra (1949), Paguyuban Siswa Among Beksa (1952), Mardawa Budaya (1962) dan Pamulangan Beksa Ngayogyakarta (1976), kemudian pada tahun 1992 kedua organisasi tari itu bergabung menjadi Yayasan Pamulangan Beksa Mardawa Budaya (YPBSM). 
Pada saat ini budaya Jawa dan masyarakatnya sedang mengalami perubahan dan pergeseran diberbagai sisi kehidupan yang dipengaruhi oleh: 1). Sosial, politik, dan budaya, 2). Semangat nasionalisme, 3). Arus indutrialisasi (Sumaryono, 2003,108-109). Perubahan itu mempengaruhi kehidupan tari klasik gaya Yogyakarta dalam menghadapi era globalisasi, karena kemajuan teknologi dan gaya hidup masyarakat modern. Masyarakat di era global lebih cenderung menerima seni modern yang lebih bersifat praktis dan menarik, sehingga mempunyai kesan penikmat tari klasik menjadi berkurang.

Walaupun minat masyarakat terhadap tari klasik gaya Yogyakarta berkurang, namun masih bisa dinikmati pada beberapa event yang diselenggarakan oleh Pemerintah Daerah Istimewa Yogyakarta. Pada Festival Sendratari, Festival Kesenian Yogyakarta yang diadakan setiap tahun, Festival Wayang Wong diselenggarakan pada tahun 1996, 2000, dan 2005. Pertunjukan tari di keraton Yogyakarta untuk upacara peringatan hari penobatan raja, menjamu pejabat pemerintahan maupun tamu mancanegara, dan setiap Minggu siang pertunjukan untuk wisatawan. Di luar keraton tari klasik dikemas untuk hiburan resepsi pernikahan, opening ceremony sebuah acara dan hiburan untuk kepentingan pariwisata di restoran, hotel-hotel berbintang, dan rumah keluarga bangsawan Dalem Jaya Kusuman dan dalem Pujakusuman.

Akibat pengaruh perkembangan politik, ekonomi dan sosial di Daerah Istimewa Yogyakarta, maka hanya dua organisasi tari gaya Yogyakarta yang telah cukup lama mampu bertahan hingga sekarang. Organisasi tari Yayasan Siswa Among Beksa berdiri sejak tahun 1952 dengan menyelenggarakan kegiatan kursus tari. Begitu pula Organisasi tari Mardawa Budaya sejak tahun 1962, kemudian tahun 1992 menjadi Yayasan Pamulangan Beksa Sasminta Mardawa, mampu bertahan sampai sekarang menyelenggarakan kursus tari dan pertunjukan sendratari Ramayana untuk wisatawan. Walaupun mengalami pasang surut, namun dua organisasi tersebut mampu mempertahankan eksistensinya hingga sekarang.

Kondisi pada saat ini bahwa kehidupan tari klasik gaya Yogyakarta perlu mendapat perhatian untuk menghadapi tantangan zaman. Seiring dengan kemajuan teknologi dan kondisi perekonomian yang tidak menentu, di era globalisasi ini bagaimanakah kegiatan organisasi tari untuk melestarikan dan mengembangkan tari klasik gaya Yogyakarta, dan bagaimanakah peranan organisasi tari dalam masyarakat yang selalu mengalami perubahan?

\section{B. Peranan Organisasi Tari dalam Pendidikan}

Sistem pendidikan di Indonesia menjelaskan bahwa tujuan pendidikan nasional adalah untuk meningkatkan kualitas manusia Indonesia, yaitu manusia yang beriman dan bertaqwa kepada Tuhan Yang Maha Esa, berbudi luhur, berkepribadian, mandiri, maju, tangguh, cerdas, kreatif, terampil, berdisiplin, beretos kerja, bertanggung jawab, profesional, dan produktif, serta sehat jasmani sosial. (Sal Murgiyanto, 2004: 153).

\begin{tabular}{|c|c|c|c|c|}
\hline No & $\begin{array}{l}\text { Aspek Joged } \\
\text { Mataram }\end{array}$ & Deskripsi & $\begin{array}{c}\text { Prinsip Pembela- } \\
\text { jaran Tari }\end{array}$ & Keterkaitan \\
\hline 1. & Sawiji & $\begin{array}{l}\text { wujud untuk selalu } \\
\text { konsentrasi dalam } \\
\text { menghadapi segala } \\
\text { kegiatan }\end{array}$ & $\begin{array}{l}\text { Pemahaman } \\
\text { Kemauan } \\
\text { Kesungguhan } \\
\text { Ketekunan }\end{array}$ & $\begin{array}{l}\text { Dalam mempelajari } \\
\text { tari harus konsentrasi } \\
\text { penuh agar apa yang } \\
\text { dipelajri dapat } \\
\text { optimal }\end{array}$ \\
\hline 2. & Greget & $\begin{array}{l}\text { ungkapan dinamika } \\
\text { dalam kehidupan } \\
\text { yang harus dilalui } \\
\text { manusia }\end{array}$ & $\begin{array}{l}\text { Pemahaman } \\
\text { Kemauan } \\
\text { Kesungguhan } \\
\text { Ketekunan } \\
\end{array}$ & $\begin{array}{l}\text { Dinamika dalam } \\
\text { kehidupan harus } \\
\text { menjadi dasar untuk } \\
\text { memahami sesuatu }\end{array}$ \\
\hline 3. & Sengguh & $\begin{array}{l}\text { kepercayaan diri } \\
\text { manusia dalam } \\
\text { segala situasi tanpa } \\
\text { harus } \\
\text { menyombongkan } \\
\text { diri }\end{array}$ & $\begin{array}{l}\text { Pemahaman } \\
\text { Kemauan } \\
\text { Kesungguhan } \\
\text { Ketekunan }\end{array}$ & $\begin{array}{l}\text { Sikap yang haru } \\
\text { dikedepankan oleh } \\
\text { setiap orang dalam } \\
\text { menghadapi segala } \\
\text { situai. Jangan merasa } \\
\text { puas sebelum apa } \\
\text {,yang diperoleh itu } \\
\text { jelas. Jangan merasa } \\
\text { bisa padahal tidak } \\
\text { bisa. Jangan merasa } \\
\text { lebih baik daripada } \\
\text { teman lainnya. }\end{array}$ \\
\hline 4. & Ora Mingkuh & $\begin{array}{l}\text { sikap pantang } \\
\text { menyerah untuk } \\
\text { menggapai sebuah } \\
\text { cita-cita }\end{array}$ & $\begin{array}{l}\text { Pemahaman } \\
\text { Kemauan } \\
\text { Kesungguhan } \\
\text { Ketekunan }\end{array}$ & $\begin{array}{l}\text { Jangan menyerah } \\
\text { sebelum dicoba. } \\
\text { Mempelajari sesuatu } \\
\text { tentu akan } \\
\text { menghadapi banyak } \\
\text { tantangan dan } \\
\text { cobaan. }\end{array}$ \\
\hline
\end{tabular}

Hasil dari pemahaman siswa terhadap kandungan yang ada dalam filosofi joged amtaram memang bervariasi, namun dari hasil angket yang dibantu guru tari sekolah tersebut menunjukkan :

a. Adanya keterkaitan yang secara signifikan memberi keyakinan kita bahwa aspek filosofis joged mataram dapat diterapkan ke dalam sistem pembelajaran tari di sekolah

b. Pemahaman joged mataram yang belum mendalam akan menyulitkan untuk memberi satu simpulan tentang korelasi dimaksud dalam penelitian semacam ini

c. Kesadaran siswa dalam mnyerap materi dapat diungkap dari hasil jawaban mereka yang rata-rata mengatakan bahwa belajar tari itu membutuhkan konsentrasi penuh.

\section{Penutup
1. Simpulan}

Berdasarkan deskripsi hasil penelitian dan pembahasan yang telahdipaparkan di atas dapat disimpulkan beberapa hal sebagai berikut:

a. Dalam konteks tari, nilai-nilai filosofis joged mataram dapat diterapkan secara 
Kegiatan tari selalu membutuhkan bantuan orang lain, yaitu penari, pemain musik, penata panggung, penata cahya, perias, penata busana, bahkan penjaga gedung dan pembersih tempat kegiatan itu diselenggarakan. Dapat dikatakan tari merupakan kegiatan kesenian yang menjadi wadah sosialisasi anakanak, dan menggugah kesadaran posisinya dalam kelompok ketika menari, secara tidak langsung mereka belajar menempatkan diri di tengah masyarakat.

\section{Pendidikan Lahir dan Batin}

Tari klasik gaya Yogyakarta diajarkan atau dipelajari sebagai dasar pendidikan lahir maupun batin bagi manusia pada umumnya, khususnya di lingkungan keraton Yogyakarta. Sumaryono mengatakan bahwa proses belajar tari, sebenarnya merupakan proses belajar kesenian yang utuh. Suatu proses yang selalu menempatkan seni pada bingkai kebudayaan. Belajar tari klasik gaya Yogyakarta merupakan sarana untuk belajar tentang tata krama, etika, dan kepribadian. (Joan Suyenaga, dkk., 1999: 69). Terutama murid-murid dari mancanegara, mereka mampu beradaptasi, bertingkah laku secara Jawa dalam pergaulannya dengan teman-teman peserta kursus tari.

Pendidikan secara lahir adalah berhubungan dengan tata-susila yaitu sopan santun di dalam pergaulan manusia. Selama belajar tari diberikan paugeran (aturan) tata gerak yang dilatih secara teratur dan dilakukan seirama dengan ritme gending yang mengiringi. Apabila hal itu dapat dikuasai dengan baik maka dalam pergaulan sehari-hari, tindak-tanduk atau gerak-geriknya akan enak dipandang, menyenagkan, dan teratur, sehingga tidak menimbulkan sifat kaku dan janggal yang menimbulkan perasaan tidak enak dalam pergaulan. Paugeran dalam tata gerak tari klasik gaya Yogyakarta disusun berdasarkan penelitian sifat tubuh manusia yang dapat mewujudkan tata gerak yang luwes dan indah, maka akan berpengaruh dalam pergaulan sehari-hari. Dalam proses pembelajaran yang cukup lama dan terus menerus akan membentuk kepribadian yang tampak pada tingkah laku yang baik. (Joan Suyenaga, dkk., 1999: 18-19).

Pendidikan secara batin adalah pada kehalusan jiwa, yaitu kehalusan budi pekerti yang meliputi cara berfikir, pandangan hidup, dalam kaitannya percaya kepada Tuhan Yang Maha Kuasa. R.M. Soedarsono dalam sebuah seminar pada tanggal 13 Nopember 2006 menyampaikan makalah yang berjudul "Kearifan Lokal Dalam Seni Pertunjukan Tradisional" mengatakan bahwa "dulu" orang Jawa, lebih-lebih dari golongan aristrocrat selalu mewajibkan anak-anak mereka belajar menari, dengan belajar tari Jawa sebenarnya seseorang juga belajar etika, etiket (tatakrama), bahasa Jawa yang terdiri dari sembilan srtata, dan sastra terutama sastra pewayangan. Secara tidak langsung nilai-nilai pendidikan tersebut akan melekat pada pribadi yang melakukan aktifitas pembelajaran seni tari, hasil pendidikan itu akan tercermin pada sikap dan perilaku sehari-hari.

Hasil kegiatan pembelajaran tari diimplementasikan pada pementasan
Dalam penelitian ini kesahihan yang digunakan adalah kesahihan yang berorintasi pada data yakni kesahihan semantik. Kesahihan semants mengukur tingkat kesensitifan suatu teknik terhadap makna-makna simbolik yang relevan dengan konteks tertentu.

Untuk kehandalan dalam penelitian ini digunakan kehandalan berdasarkan kemunculan kembali (reproducibility). Kemunculan kembal menunjukkan seberapa jauh suatu proses dapat diciptakan kembali dalam berbagai lingkungan, pada tempat berbeda, menggunakan pengkodean yang berbeda. Teknik kemunculan kembali dalam penelitian ini dilakukan dengan pembacaan dan interpretasi berulang-ulang oleh peneliti. Dari pembacaan intensif itu diharapkan dapat diperoleh hasil yang memenuhi kriteria kehandalan.

\section{Hasil Penelitian dan Pembahasan}

Penelitian ini berusaha mengungkap sejauh mana implementasi nilai-nilai filosofis joged mataram ke dalam sistm pembelajaran tari di SMP Kota Yogyakarta. Nilai-nilai filosofis secara implisit telah tercakup dalam perilaku kehidupan masyarakat, khususnya para pelaku seni tari. Pembelajaran seni tari merupakan salah satu proses untuk mencapai hasil yang optimal. Dengan berbagai metode yang tepat proses pembelajaran dapat dicapai dengan maksimal. Permasalahan yang akan dibhas dalam penelitian ini bagaiaman mengimplementasikan nilai-nilai joged mataram itu ke dalam sistem pembelajaran tarinya.

Untuk memudahkan analisis, dalam penelitian ini nilai-nilai filosofis joged mataram akan diklasifikasi menjadi empat bagian yakni : 1) Sawiji ; 2) Greget ; 3) Sengguh ; 4) Ora Mingkuh. Dari klasifikasi itu kita jabarkan sesuai dengan kehidupan di sekitar kita. Berikut ini merupakan identifikasi muatan nilai-nilai filosofis dalam joged mataram.

\begin{tabular}{|l|l|l|}
\hline No & \multicolumn{1}{|c|}{ Klasifikasi } & \multicolumn{1}{|c|}{ Deskripsi } \\
\hline 1. & Sawiji, & $\begin{array}{l}\text { wujud untuk selalu konsentrasi dalam menghadapi } \\
\text { segala kegiatan }\end{array}$ \\
\hline 2. & Greged & $\begin{array}{l}\text { ungkapan dinamika dalam kehidupan yang } \\
\text { harus dilalui manusia }\end{array}$ \\
\hline 3. & Sengguh & $\begin{array}{l}\text { kepercayaan diri manusia dalam segala situasi } \\
\text { tanpa harus menyombongkan diri }\end{array}$ \\
\hline 4. & Ora mingkuh & $\begin{array}{l}\text { sikap pantang menyerah untuk menggapai } \\
\text { sebuah cita-cita }\end{array}$ \\
\hline
\end{tabular}

\section{Hubungan antaraspek dalam Filosofi Joged Mataram}

Dari empat aspek dalam joged mataram yang ada dapat kita luihat keterkaitan satu sama lain dalam mendukung kekuatan menjadi sebuah dasar pijakan joged yang disebut filosofi. Empat dasar dari deskripsi itu dapat kita uraikan sebagai berikut: 
sendratari Ramayana untuk paket wisata. Namun demikian bentuk-bentuk tari itu tidak meninggalkan paugeran atau norma pada tari klasik gaya Yogyakarta.

Pada tingkat SD, SLTP, SLTA, SMK, maupun perguruan tinggi menggunakan tarian ciptaan Rama Sas sebagai materi pelajaran. Bentuk tari yang digunakan untuk materi pelajaran di sekolah diterapkan untuk siswa puteri maupun putera. Materi tari puteri adalah tari golek Surungdayung untuk tingkat SD, tari golek Kenyotinembe untuk tingkat SLTP, sedangkan tari Golek Asmaradana untuk tingkat SLTA. Materi putera tari Cantrik atau Kuda-kuda untuk tingkat SD, tari Klana Raja atau Klana Alus untuk tingkat SLTP, sedangkan tari Klana Topeng Gagah atau Klana Topeng Alus untuk tingka SLTA. Materi tari yang digunakan pada tingkat perguruan tinggi adalah Beksan Srikandi versus Suradewati, Srimpi Pandelori, Klana Topeng Gagah, dan Klana Topeng Alus, dan sebagainya.

Pada tahun 1962 berdirilah Konservatori Tari (KONRI) dan tahun 1963 berdirilah Akademi Seni Tari Indonesia. Sekolah kejuruan tingkat SLTA dan perguruan tinggi khusus seni tari, karawitan, dan pedalangan tersebut merupakan usaha para pakar kesenian agar kesenian dapat dikembangkan menjadi bidang ilmu. Pada saat itu pula siswa-siswi KONRI dan ASTI menjadi peserta kursus di organisasi tari klasik gaya Yogyakarta yang ada di Yogyakarta. Mereka mendukung perkembangan organisasi tari, karena membantu mereka untuk meningkatkan olah keterampilan tari dan karawitan.

Pada perkembangan berikutnya kegiatan pada organisasi dapat digunakan sebagai tempat praktek kerja lapangan bagi siswa SMKI (sekarang menjadi SMK

I Bantul) yang bermanfaat untuk memberikan pengalaman pada siswa. Mereka perlu belajar dan melihat secara langsung pada lembaga non formal yang menyelenggarakan kegiatan pembelajaran tari, sekaligus mengetahui tentang manajemen pertunjukan pada sebuah organisasi tari.

Organisasi tari Yayasan Siswa Among Beksa (YASAB) maupun Yayasan pamulangan Beksa sasminta Mardawa (YPBSM) memberikan manfaat pada mahasiswa Jurusan Pendidikan Seni Tari Universitas Negeri Yogyakarta (UNY) dan mahasiswa Jurusan Seni Pertunjukan Institut Seni Indonesia (ISI) Yogyakarta untuk menimba belajar tari pada nara sumber tari klasik gaya Yogyakarta. Mahasiswa mendapat pengalaman untuk merekonstruksi tarian yang sudah cukup lama tidak dipentaskan yang dibuat rekaman aoudio fisual, misalnya tari Golek Clunthang, tari Batik, Beksan Srikandi Larasati, Beksan Srikandi Bisma, Srimpi Pandelori, Srimpi Gambirsawit, Bedaya Angron Sekar, Bedaya Sangupati, dan sebagainya.

Manfaat yang diperoleh mahasiswa diharapkan tidak hanya sekedar keterampilan teknik tari saja. Setelah mendapat bimbingan dari nara sumber yang patut dihandalkan, maka diharapkan akan mendapatkan pendidikan tentang nilainilai budaya dan wawasan yang lebih luas dari pembelajaran tari yang diikutinya.
Beberapa nilai itu antara lain nilai praktis, nilai sosial, nilai religius, nilai susila atau norma, nilai kultural, nilai estetis dan nilai yang bersifat konsepsional. Nilai dapat saling berkaitan membentuk suatu sistem dan antara satu dengan yang lain koheren serta mempengaruhi segi kehidupan manusia. Selanjutnya Sinarto (dalam Sutikno, 1999 : 168) mengatakan bahwa nilai-nilai kehidupan adalah norma yang berlaku dalam masyarakat, misalnya adat kebiasaan dan sopan santun. Berdasarkan uraian di atas dapat bdisimpulkan bahwa nilai adalah sifat atau hal-hal yang penting dan berguna bagi manusia dan kemanusiaan. Nilai berkaitan dengan masalah kebaiakn dan menunjuk pada sikap orang terhadap sesuatu hal yang baik. Oleh karena itu nilai merupakan kadar relasi posotof antar sesuatu hal dengan orang tertentu, termasuk nilai susila atau moral.

b. Makna Joged Mataram

Joged adalah tari, Mataram adalah sumber dari asal tarin itu. Jadi Joged Mataram adalah hasil karya tari yang bersumber dari kerajaan mataram. Joged Mataram secara lahir dapat pula diartikan sebagai gaya dalam tari. Orang Yogyakarta sering menyebut gaya tari Yogyakarta dengan gaya Mataraman. Hal ini terkait dengan latar belakang historis perjalanan tari klasik gaya Yogyakarta.

Secara substansial, joged mataram merupakan isi atau "roh" dari bentuk fisik yang disebut dengan tari gaya Yogyakarta. Dalam paparannya GBPH Suryobrongto menerapkan dasar pemahaman tari gaya Yogyakarta sebagai way of life bagi orang yang menekuninya (lihat Fred Wibowo, 1981 : 47) Maka tak mengherankan kalau para pendukung tari di kraton tempo dulu lebih mengutamakan penjiwaan dari pada teknis menarinya. Menari bukan tujuan, tetapi hanya sarana membentuk diri (baca : sopan santun) Kandungan isi yang dalam inilah yang sering disebut dengan filosofi dari tari gaya Yogyakarta yang terdiri dari empat hal yaitu : sawiji, greget, sengguh dan ora mingkuh (Suryobrongto, 1971:3)

\section{c. Pembelajaran Tari}

Menurut Kussudiardja (1992) untuk melakukan tari perlu mempunyai bekal terlebih dahulu, agar dalam mempelajari seni tari ada sasaran yang akan dituju. Pendapat ini relevan dengan kenyataan yang terjadi, karena belajar tari harus menggunakan pikiran, perasaan, dan badan sebagai alat pokok. Selain itu, masih ada beberapa hal yang perlu diperhatikan dalam mempelajari tari, yaitu : (a) pengertian, artinya memahami tari bukan sekedar permainan tetapi merupakan bagian dari kehidupan, sehingga akan menumbuhkan kesadaran untuk meletakkan seni tari pada kedudukannya yang wajar, (b) kemauan, adanya keinginan atau hasrat untuk belajar tari, bukan karena terpaksa atau dipaksa, dan (c) kesungguhan, pelaksanaan yang ideal juga harus dilakukan dengan sungguh-sungguh, disiplin, tekun dan rajin. Lebih lanjurlt Kussudiardja menjelaskan bahwa penari selain menguasai teknik tari harus matang dalam menjiwai isi tariannya dan harus bisa menguasai panggung. Sementara seorang guru taru harus bisa menguasai teknik 
Dalem Pujakusuman sebagai tempat kegiatan pembelajaran tari klasik gaya Yogyakarta dan pertunjukan sendratari Ramayana, tempat ini patut dikunjungi oleh wisatawan. Yogyakarta merupakan kota tujuan wisata nomor dua setelah pulau Bali. Pertunjukan drama tari Ramayana yang disajikan selama satu setengah jam telah dikemas dan disajikan sebagai pertunjukan untuk wisatawan. Untuk itu perlu memperhatikan kriteria seni pertunjukan untuk wisata yang mempunyai ciri khusus yaitu, singkat, padat, dan murah. Hal ini perlu dipertimbangkan dengan memperhatikan kondisi dan selera wisatawan bahwa wisatawan mempunyai waktu terbatas untuk menikmati pertunjukan, wisatawan tidak memerlukan bentuk pertunjukan secara utuh, mereka ingin mempunyai kesan baik dan menarik dengan pertunjukan yang dilihatnya.

Pada tahun 1981 Mardawa Budaya bekerjasama dengan Gradika Pariwisata Yogyakarta (GYP) telah berhasil menyelenggarakan pertunjukan sendratari Ramayana yang dipadati oleh penonton asing. Pertunjukan itu dimulai pada 4 April 1981, kemudian diselenggarakan setiap hari Rabu, Jumat. Dalam perkembangannya disampaikan oleh Hasbullah Ashari, seorang pengurus GYP bahwa lama tinggal seorang wisatawan di Yogyakarta rata-rata dua hari dan menginginkan mendapatkan hiburan malam yang bercirikan Yogyakarta (Kompas, 9 April 1981)

Hal itu mendapat perhatian dari GYP, maka akan diperpanjang dengan meyelenggarakan hiburan malam yang kontinyu, yaitu pertunjukan di Mardawa Budaya pada hari Senin, Rabu, dan Jumat. Pengunjung pertunjukan di Pujakusuman semakin padat pada bulan musim turis bulan Juli dan Agustus. Namun mulai 1990-an jumlah penonton asing mulai menurun, kemudian pada tahun 1993 GYP melepas kerjasamanya, sehingga manajemen pertunjukan dikelola secara mandiri oleh YPBSM. Pihak pengurus dan pendukung pertunjukan membuat kesepakatan, bahwa untuk sementara seluruh pendukung mendapatkan honor Rp 2000,- baik ada penonton maupun tidak sama sekali. (tahun 1984-1993 penulis masih aktif sebagai penari di YPBSM).

Pada tahun 1981-1990-an Mardawa Budaya bisa dikatakan sukses mencapai puncaknya, karena bisa mendatangkan tamu cukup banyak bahkan penonton rela duduk dilantai sekitar pendapa Pujakusuman. Namun sejak tahun 1998 gejolak politik dan perekonomian di Indonesia semakin tidak menentu, maka berakibat turunnya jumlah wisatawan yang berkunjung di Indonesia. Hal ini mempunyai dampak pada menurunnya jumlah pertunjukan untuk wisatawan, sehingga mengurangi pendapatan bagi yang mempunyai profesi penari di restoran, hotel-hotel berbintang, maupun pertunjukan untuk wisatawan di Dalem

Jayakusuman dan Dalem Pujakusuman.

\section{Pertunjukan Wisata di Era Global}

Pada tahun 1998 situasi dan kondisi semakin buruk dengan adanya peristiwa demonstrasi secara besar-besaran yang menuntut lengsernya Presiden 